Filozofski fakultet

Doktorske studije jezika i književnosti

jelenabadovinac@gmail.com

Nebojša S. Vlaškalić

Univerzitet u Novom Sadu

Filozofski fakultet, Odsek za romanistiku

nebojsa.vlaskalic@ff.uns.ac.rs

\title{
ELEMENTI KULTURE I CIVILIZACIJE U UDŽBENIKU ITALIJANSKOG JEZIKA NUOVO ESPRESSO 1 - VIDEO CORSO I CAFFÈ CULTURALE ${ }^{1}$
}

APSTRAKT: U ovom istraživanju ćemo izdvojiti elemente italijanske kulture i civilizacije prikazane u kratkim video-zapisima (Video corso) i zasebnim, namenski osmišljenim, tekstualnim celinama (Caffè culturale) koji prate sve nastavne jedinice u udžbeniku italijanskog jezika Nuovo Espresso 1. Cilj rada je da analizira ovaj korpus, te naglasi njegovu didaktičku korisnost u procesu učenja i usvajanja italijanskog jezika i kulture. Imajući u vidu raznolikost materijala koji ćemo analizirati, razvrstaćemo ga po tematskim celinama kako bismo preglednije predočili koliko je učenje stranog jezika neodvojivo od učenja o ciljnoj kulturi. Istražićemo kako tekstualni i video-prikazi dopunjavaju kulturološke aspekte jezika, te olakšavaju proces učenja i usvajanja italijanskog jezika i kulture na početnom nivou, što doprinosi kvalitetnijoj interkulturalnoj kompetenciji učenika pri komunikaciji s izvornim govornicima.

Ključne reči: italijanski jezik i kultura, usvajanje stranog jezika, interkulturalna kompetencija, komunikacija, video i tekst.

\section{ELEMENTS OF CULTURE AND CIVILIZATION IN THE ITALIAN LANGUAGE TEXTBOOK NUOVO ESPRESSO 1 - VIDEO CORSO AND CAFFÈ CULTURALE}

ABSTRACT: In this research, we will single out the elements of Italian culture and civilization presented in short videos (Video corso) and separate, intentionally designed, textual units (Caffè culturale) that accompany all teaching units in the Italian language textbook Nuovo Espresso 1. The aim of this research is to analyze this corpus and

\footnotetext{
${ }^{1}$ Rad je prezentovan na Šestoj međunarodnoj konferenciji Interkulturalnost u obrazovanju - Interkult 2020, održanoj onlajn 3. oktobra 2020. godine, u organizaciji Pedagoškog zavoda Vojvodine.
} 
emphasize its didactic usefulness in the process of learning and acquisition of Italian culture. Keeping in mind the variety of material that we will analyze, we will classify it by thematic units in order to present more clearly how learning a foreign language is inseparable from learning about its culture. Through textual and video presentations we will emphasize how the cultural aspects of language complement each other and facilitate the process of learning Italian language and culture at the elementary level. This approach will ultimately lead to better intercultural competence when communicating with native speakers.

Key words: Italian language and culture, foreign language acquisition, intercultural competence, communication, video and text.

\section{UVOD}

Budući da ćemo se u radu baviti elementima italijanske kulture i civilizacije, čije je razumevanje i usvajanje od presudnog značaja za celovito savladavanje i upotrebu italijanskog jezika kao stranog, u našem pristupu dve navedene kategorije će se međusobno preplitati. Veze između jezika i kulture neraskidive su, što ističe i Marić, ukazujući na Skotijevo mišljenje po kojem ,,jezik omogućava razvoj kulture, a razvojem kulture se razvija i jezik" (Scotti u Marić 2006: 909). Za komplementarni razvoj ova dva društvena fenomena ključna figura jeste njihov korisnik, odnosno pojedinac u društvenoj zajednici u kojoj oni nastaju i razvijaju se. Nastavu stranog jezika ne treba ograničavati isključivo na sticanje komunikativnih kompetencija i usvajanje jezičke građe, već je neophodno sagledati širi društveni kontekst, te uzeti u obzir i jezičku sociolingvističku dimenziju. Imajući u vidu da je proces učenja stranog jezika u najvećoj meri baziran na radu nastavnika, uz korišćenje osnovnog didaktičkog materijala tokom nastave, jasno je da se vanjezički elementi mnogo teže savladavaju. Stoga, podučavanje stranog jezika treba obogatiti raznovrsnim posrednim sredstvima za usvajanje vanjezičkih elemenata, poput informativnih $\mathrm{i}$ edukativnih tekstova, te multimedijalnog sadržaja, o čemu će u ovom radu još biti reči.

Nakon istraživanja korelacija između jezika, kulture i civilizacije u prvom poglavlju ovog rada, drugi deo našeg istraživanja posvetićemo učenju stranih jezika i interkulturalnoj kompetenciji. U trećem poglavlju bavićemo se verbalnom i neverbalnom komunikacijom kao obeležjem italijanske kulture. Analizirani korpus predstavićemo u poslednjem delu našeg rada. Analizirajući tekstualne i videoceline u udžbeniku Nuovo Espresso 1, istaći ćemo kako kulturni aspekti upotpunjavaju jezičke, te tako olakšavaju proces učenja italijanskog jezika i kulture na početnom nivou, istovremeno doprinoseći boljoj interkulturalnoj kompetenciji s izvornim govornicima. 


\section{JEZIK, KULTURA I CIVILIZACIJA}

Zbog njegove višeznačnosti, pojam jezika nije jednostavno odrediti, stoga ćemo se pozvati na tvrdnju Bugarskog, koji smatra da jezik predstavlja ,čoveku svojstvenu sposobnost društvenog opštenja putem artikulisanog sistema verbalnih znakova koji omogućuje oblikovanje misaonih sadržaja i njihovo prenošenje u vidu suvislih govornih poruka" (Bugarski 2005: 10). Bugarski dalje naglašava da je ljudska sposobnost da se služi jezikom genetski utemeljena, ali da se ona ostvaruje zahvaljujući okruženju u kojem se određeni jezik govori (Bugarski 2005: 10-11). Dakle, čovek od rođenja spontano razvija tu sposobnost, ali koji će jezik govoriti, najpre zavisi od okoline, odnosno zajednice u kojoj odrasta.

Od svog postanka čovek se bavi stvaranjem, a sve njegove tvorevine, među kojima je i jezik, možemo u izvesnom smislu posmatrati kao deo kulture. Polazeći od činjenice da je ,pojam kulture širok i [...] lako podložan manipulaciji”, Dudaš smatra da je nemoguće precizno definisati kulturu (Dudaš 2006: 159). Kultura je polisemična leksema koju su pokušali da definišu mnogi naučnici - tako su antropolozi Kreber i Klakhon, nakon što su prikupili i analizirali više stotina definicija ovog pojma, ponudili i sopstvenu definiciju:

„Kultura se sastoji od eksplicitnih i implicitnih obrazaca ponašanja koji se stiču i prenose putem simbola, tvoreći razlikovna dostignuća ljudskih grupa [...]; suštinsko jezgro kulture sastoji se od tradicionalnih [...] ideja i pogotovu vrednosti koje im se pridružuju; kulturni sistemi se mogu, s jedne strane, smatrati proizvodima delanja, a s druge strane uslovljavajućim elementima budućeg delovanja" (Kroeber \& Kluckhohn u Durbaba 2016: 17-18).

Izučavajući odnos kulture i civilizacije, zapitali smo se da li su ovi pojmovi možda sinonimi, što implicira i antropolog Edvard Barnet Tejlor koji kaže da „kultura ili civilizacija, sagledana u širokom etnografskom smislu predstavlja složenu celinu koja uključuje znanje, uverenja, umetnost, moral, zakon, običaje i bilo koje druge sposobnosti ili navike koje čovek stiče kao član društva" (Tylor 1920: 1). Odnosom kulture i civilizacije bavio se i Bugarski. Budući da su čovekove tvorevine duhovne i materijalne prirode, on smatra da materijalna dobra, poput naučno-tehnološkog napretka, spadaju u civilizaciju nekog društva, te je njen stepen razvijenosti moguće porediti s nekom drugom civilizacijom. S druge strane, duhovna dobra čine kulturu, koja je od suštinske važnosti za život jedne zajednice, te ne može biti merljiva² (Bugarski 2006: 32). Balboni, pak, pomenuta dva pojma

\footnotetext{
${ }^{2}$ Razlika se jasno vidi i ukoliko se dva navedena pojma etimološki analiziraju: „,reč kultura (lat. cultūra „sađenje, obrađivanje”) upućuje na negovanje, u poljoprivrednom, biološkom
} 
definiše iz perspektive podučavanja jezika, te naglašava da se o pojmu kulture može govoriti kao o načinu života (engl. way of life), dok se civilizacija odnosi na bitne kulturne vrednosti, ideje, te način organizacije ličnog i društvenog života, koji su opšteprihvaćeni. On dodaje da se problemi u jednostavnoj komunikaciji zasnivaju na kulturološkim razlikama, dok je kod dubljih odnosa komunikacija otežana civilizacijskim distinkcijama (Balboni 2008: 1). Govoreći o vezama između komunikacije i kulture, komunikolog Edvard Hol ova dva pojma dovodi u istu ravan, ističući da je „kultura komunikacija, a komunikacija kultura.” (Hol u Durbaba 2016: 275).

Premda su razlike između ova dva pojma evidentne, u našem radu oni će biti posmatrani kao komplementarni. Stoga ćemo civilizaciju smatrati celovitijim pojmom i posmatrati je kao zapadnoevropsku, a italijansku kulturu kao njen sastavni deo. Budući da će predmet naše analize biti korpus namenjen početnom nivou učenja italijanskog jezika, elemente kulture i civilizacije u ovom istraživanju podelićemo na nekoliko celina, o čemu će biti reči u poslednjem poglavlju rada.

\section{UČENJE STRANOG JEZIKA I INTERKULTURALNA KOMPETENCIJA}

Kako bi se ostvarila delotvorna i nedvosmislena komunikacija s izvornim govornicima, učenje stranog jezika trebalo bi upotpuniti učenjem o kulturološkim i društvenim prilikama naroda čiji se jezik uči. U pokušaju da se prevaziđu eventualni problemi koji se mogu javiti u međusobnom razumevanju, nije dovoljno samo pasivno prihvatati različitosti, već je neophodno negovati konstantnu interakciju između pripadnika različitih kultura. Neophodnost takve interakcije vezuje se za interkulturalnost koja ,podrazumeva suočavanje s problemima koji se javljaju u odnosima između nosilaca različitih kultura, njihovo prihvatanje i poštovanje" (Đurić, Đurić \& Tomašević 2021: 22). Interkulturalnost i plurilingvizam imaju i institucionalno utemeljenje u načelima jezičke politike ujedinjene Evrope, odlučne da neguje raznolikost i bogatstvo jezika koji se u njoj govore. Učenje stranih jezika, dakle, ima i svoju višu namenu, kroz ostvarivanje što uspešnijeg sporazumevanja i saradnje građana Evrope u raznorodnim oblastima (Đorović 2014: 250). U tom smislu, Stanić i Blatešić naglašavaju da je nastava stranog jezika od posebne važnosti za razvijanje interkulturalne kompetencije,

ili nekom od izvedenih značenja, dok reč civilizacija (lat. cīvis „građanin”) ukazuje na specifičnosti urbane kulture, na gradski život sa njemu svojstvenom organizacijom" (Bugarski 2006: 33). 
neophodne pri direktnim i indirektim kontaktima s predstavnicima strane kulture (Stanić \& Blatešić 2019: 326). Treba naglasiti i značaj mobilnosti učenika, odnosno stvaranja prilika da kroz boravak u zemlji čiji jezik uče utvrde stečena i usvoje nova znanja ${ }^{3}$. Na taj način stiču se bogata iskustva, značajna ne samo za nastavak učenja stranog jezika u matičnoj zemlji, već i za bolje međusobno razumevanje i toleranciju između pripadnika različitih kultura.

Kada se uči maternji jezik, uči se implicitno jer se sluša i imitira jezik koji se čuje, pa se ceo proces odvija spontano. Nasuprot tome, pri učenju stranog jezika učenik ne može automatski da stvara rečenice, niti da ih razume u određenom kontekstu, a osim toga često ne uspeva pravilno da shvati neverbalnu komunikaciju na stranom jeziku. Stoga je neophodno da te veštine dodatno razvija (Vilić 2006: 907), kako bi postao ravnopravan sagovornik u komunikaciji s izvornim govornikom. S obzirom na to da je većina didaktičkog materijala namenjenog učenju stranog jezika i dalje zasnovana na komunikativnom pristupu, podsećamo da je u tom kontekstu osnovni cilj nastave sticanje komunikativne kompetencije. U tom procesu, pored sticanja znanja o gramatičkim i leksičkim strukturama, kao i jezičkim funkcijama ciljnog jezika, učenik treba da nauči kako da primenjuje stečena znanja u odgovarajućim komunikativnim situacijama. Stoga je od izuzetne važnosti da nastavnik u kontinuitetu bogati postojeći didaktički materijal adekvatnim dodatnim sadržajima, kojima će podsticati učenika da razmišlja o kulturi koju upoznaje, ali i da mu omogući direktne ili indirektne interkulturalne susrete, kroz povezivanje s izvornim govornicima ciljnog jezika. Upravo će ta interakcija biti prvi korak u sticanju interkulturalne kompetencije ${ }^{4}$, za koju Durbaba ističe da ,se smatra sposobnošću pojedinca da komunicira, deluje i stvara u socijalnom okruženju drugih kulturno različitih pojedinaca i grupa" (Durbaba 2016: 275). Kada se čin učenja i savladavanja stranog jezika posmatra kroz ovu širu prizmu postaje jasno da ,ne postoji komunikativna kompetencija bez adekvatne interkulturalne kompetencije" (Balboni 2008: 3) ${ }^{5}$.

\footnotetext{
${ }^{3}$ Značaj mobilnosti mladih, a pre svega studenata, istaknut je i u Bolonjskoj deklaraciji o visokom obrazovanju, pre više od dve decenije, tako da su pokrenuti još uvek aktuelni raznovrsni programi za razmenu studenata (kao što su Erasmus+ i Erasmus Mondo), s ciljem da se studentima omogući studiranje u drugačijem akademskom okruženju.

${ }^{4}$ Premda postoji terminološka neusaglašenost oko pojmova interkulturno/interkulturalno, te interkulturnost/interkulturalnost, $\mathrm{u}$ radu ćemo koristiti pojmove interkulturalno $\mathrm{i}$ interkulturalnost.

${ }^{5} \mathrm{U}$ odnosu na komunikativnu kompetenciju, Durbaba interkulturalnu kompetenciju smatra primarnom u pedagoškom smislu, te ističe kako se ona „ne vezuje isključivo za pojmovni repertoar nastave stranih jezika, već zahteva brojna interdisciplinarno shvaćena umeća. U
} 
Uzimajući u obzir činjenicu da učenik počinje da uči strani jezik $\mathrm{s}$ određenim ličnim stavovima i predubeđenjima o tom jeziku, odnosno njegovim izvornim govornicima, proces sticanja interkulturalne kompetencije treba da se sprovodi postepeno „od sticanja znanja o drugoj kulturi, preko razvijanja svesti o drugačijim perspektivama posmatranja sebe i drugih, da bi se došlo do interkulturne interakcije i posredovanja" (Momčilović 2013: 527). Momčilović podseća na jasno određene faze u postizanju interkulturalne kompetencije koje navode Fenes i Hepgud: „etnocentrizam $\rightarrow$ priznanje $\rightarrow$ svest $\rightarrow$ razumevanje $\rightarrow$ prihvatanje i poštovanje $\rightarrow$ promena $\rightarrow$ interkulturna kompetencija" (Fenes \& Hepgud u Momčilović 2013: 527), što potvrđuje složenost ovog procesa. Mada je savladavanje navedenih faza individualno i zavisi od stavova koje učenik ima o sopstvenoj, ali i o ciljnoj kulturi, za njihovo uspešno savladavanje presudan je nastavnik koji bi trebalo vešto da usmerava učenike na putu ka sticanju interkulturalne kompetencije.

\section{VERBALNA I NEVERBALNA KOMUNIKACIJA KAO OBELEŽJE ITALIJANSKE KULTURE}

Kako bismo bolje sagledali odnos kulture i komunikacije kod Italijana, treba naglasiti da su složene društveno-političke prilike na Apeninskom poluostrvu imale značajan uticaj na raznovrsnost jezičkog izraza italijanske govorne zajednice. Kroz kritički stav prema svom narodu, sociolog Livolsi iznosi da se kolektivno nasleđe ne može negirati i ignorisati. Govoreći o danas prisutnim razlikama između severnog, bogatijeg, i južnog, siromašnijeg dela Italije, te o teškom putu od ujedinjenja do današnjih dana ${ }^{6}$, italijanski sociolog zaključuje da ne postoji samo jedna Italija, već mnoge (Livolsi 2011: 12-13). Ovakav stav može se analizirati iz različitih uglova, a nama je zanimljiv u sociolingvističkom smislu. S tim u vezi, treba istaći da, pored standardnog jezika, Italija obiluje mnoštvom dijalekata koji se mogu razlikovati na regionalnom, ali i na lokalnom nivou. Svaki lokalni jezik oslikava posebnu društvenu dimenziju - od različitog izgovora, leksike i gramatike,

sinergiji sa komunikativnom kompetencijom, ostvarenom u nastavi/učenju stranih jezika, nastaje interkulturna komunikativna kompetencija" (Durbaba 2016: 277).

${ }^{6}$ Smatramo da je ovde važno podsetiti se nekih od najznačajnijih političkih događaja za Italiju, kao što su: Ujedinjenje Italije (1861. godina), Dučeova diktatura (od 1922. do 1943. godine), političko-ideološki sukobi nakon Drugog svetskog rata, eskalacija terorističkih napada (ubistvo premijera Alda Mora 1978. godine), korupcionaške afere (devedesetih godina $\mathrm{XX}$ veka), itd. 
preko raznolikih običaja i tradicije, do gastronomije, koja zauzima posebno mesto u životu svih Italijana. Iako se učenje italijanskog kao stranog jezika zasniva na izučavanju njegovog standardnog oblika, smatramo da je važno naglasiti da na njega utiču mnogobrojne dijalekatske karakteristike, neodvojive od kulturoloških i civilizacijskih elemenata koji su predmet našeg istraživanja.

Kultura jednog naroda ogleda se u načinu komunikacije, kako između sunarodnika tako i sa pripadnicima drugih naroda. Ističući značaj komunikacije za očuvanje ljudskog postojanja, Trebješanin i Žikić navode da je ona „temelj svih društvenih odnosa i svake interpersonalne interakcije” (Trebješanin \& Žikić 2015: 13). Budući da se ,govorna komunikacija odvija kroz dva simultana komunikaciona kanala: verbalni (lingvistički) kanal i neverbalni (nelingvistički) kanal" (Jovičić u Jovičić, Kašić \& Đorđević 2006: 443), mi ćemo ih u ovom delu rada analizirati. Pri verbalnoj komunikaciji poruka se prenosi jezičkim simbolima, koji imaju poseban značaj u izučavanju stranih jezika. Međutim, pored ovih lingvističkih kodova, prema Balboniju, prenose se i vizuelni, kinezički, proksemički kodovi, kao i poruke koje se šalju kroz način oblačenja i statusne simbole (Balboni 2008: 6). U tom slučaju govorimo o neverbalnoj komunikaciji, čije je kodove jednako važno savladati pri učenju stranog jezika, radi što uspešnije interakcije sa sagovornikom. Svaku društvenu zajednicu karakteriše posebna neverbalna komunikacija, koja raspolaže univerzalnim, ali i lokalnim simbolima, razumljivim isključivo njenim pripadnicima.

U nastavi italijanskog kao stranog jezika na početnom nivou, posebnu pažnju treba posvetiti i tumačenju neverbalne komunikacije, koja kod Italijana ima značajnu ulogu u prenošenju informacije u komunikacionom kanalu. Pored univerzalnih telesnih pokreta u komunikaciji, bitno je uočiti i specifične oblike kinezičke komunikacije, izrazito zastupljene kod italijanskih govornika osobenost gesta, facijalne ekspresije, posturalne i taktilne komunikacije, a koji simultano prate verbalnu komunikaciju. S obzirom na značajnu ulogu koju verbalna $\mathrm{i}$ neverbalna komunikacija imaju u sticanju komunikativne i interkulturalne kompetencije, $\mathrm{u}$ analizi našeg korpusa izdvojićemo najznačajnije elemente verbalne i neverbalne komunikacije kod Italijana, za koje autori knjige Nuovo Espresso 1 smatraju da bi učenici ovog jezika trebalo da usvoje na početnom nivou učenja.

\section{OPIS I ANALIZA KORPUSA}

Namenjen učenicima italijanskog kao stranog jezika na početnom nivou (A1), udžbenik Nuovo Espresso 1, prvi je u istoimenoj ediciji udžbenika 
italijanskog jezika za strance, u izdanju izdavačke kuće Alma Edizioni iz Firence, koja, pored ovog, u ponudi ima i udžbenike za ostale nivoe učenja jezika (A2, B1, B2, C1 i C2). Zapravo, naš korpus je prerađeno i dopunjeno izdanje udžbenika Espresso 1, koje je pod novim nazivom prvi put štampano 2001. godine. Ovo novo izdanje, s unapređenim vizuelnim aspektom, sadrži veliki broj zanimljivih ilustracija, fotografije poznatih gradova i mapu Italije. Za početni nivo pripremljen je didaktički materijal za oko devedeset sati nastave, koji pored udžbenika obuhvata i CD s dijalozima, DVD s video-kursom i video-gramatikom, radnu svesku s dodatnim vežbama, kao i vodič za nastavnika ${ }^{7}$. Kao što je navedeno u uvodnom delu pomenutog vodiča, prvobitna verzija ove edicije udžbenika izazvala je odlične reakcije korisnika, pre svega zbog svog raznovrsnog sadržaja, jasnih objašnjenja, prilagođenosti učenicima i metodološkog pristupa (Ziglio \& Rizzo 2001: 2). Udžbenik Nuovo Espresso 1 koristi se već duži niz godina na Filozofskom fakultetu Univerziteta u Novom Sadu. Studenti osnovnih akademskih studija kao izborni predmet mogu da biraju italijanski jezik tokom dve godine (studenti svih filoloških i nefiloloških studijskih grupa), odnosno tokom sve četiri godine studiranja (studenti studijskog programa Francuski jezik i književnost sa drugim romanskim jezikom i kulturom). Nastavni materijal u udžbeniku podeljen je na deset lekcija, u okviru kojih se obrađuju različite teme, praćene brojnim audio-zapisima i zadacima prilagođenim svakoj gramatičkoj jedinici, s posebnim akcentom na proširenje leksičkog fonda. Na kraju svake nastavne jedinice nalazi se sažetak gramatičkih pravila $\mathrm{s}$ najznačajnijim morfosintaksičkim elementima, jezičkim konstrukcijama i karakterističnim izrazima, koji predstavlja neku vrstu podsetnika i olakšava učenje.

Ukoliko se nakratko osvrnemo na prethodno izdanje, uočavamo da je prepoznata potreba da se u savremenoj glotodidaktici primeni aktuelniji pristup, te je novi udžbenik dopunjen i multimedijalnim materijalom. Video-kurs (Video corso) sačinjen je od deset kratkih epizoda, u kojima su prikazane svakodnevne situacije iz života grupe italijanskih studenata. Pored ovih igranih epizoda, on obuhvata i video-zapise u kojima izvorni govornik pojašnjava najvažnije gramatičke elemente $u$ datoj lekciji. Nova verzija udžbenika obogaćena je i kulturološkim sadržajima koji prate svaku nastavnu jedinicu, pod nazivom

\footnotetext{
${ }^{7}$ Ovi podaci preuzeti su sa sajta izdavača v. https://www.almaedizioni.it/it/catalogo/scheda/ nuovo-espresso-1/ - pristupljeno 1.9. 2020. godine.
} 
Kulturološki kafe (Caffè culturale) što u staroj verziji nije bio slučaj ${ }^{8}$. Nakon druge, pete, sedme i desete nastavne oblasti, autori udžbenika predlažu po tri dodatne aktivnosti:

1) igru, kroz koju učenik, zabavljajući se, ima priliku da ponovi najvažnije leksičke i morfosintaksičke elemente;

2) pregled usvojenih znanja ( ̌́ta znam da uradim?; Šta sam novo naučio/la?);

3) predlog da učenik uradi konkretan zadatak (da napiše upitnik, izvrši pretragu na internetu, popuni svoju biografiju i sl.) (Ziglio \& Rizzo 2001: $6)$.

Poslednji deo udžbenika sastoji se iz niza morfosintaksičkih i leksičkih vežbi uz svaku lekciju, kao i četiri testa, predviđena za samostalni rad i proveru znanja (s datim rešenjima). Nakon toga, učeniku je ponuđen pregled celokupne gramatike obrađene u udžbeniku.

Kada je u pitanju metod rada, ovaj udžbenik prilagođen je komunikativnom pristupu u nastavi. Mada Nuovo Espresso 1 karakteriše raznovrsnost materijala, koji podstiče razvijanje sve četiri jezičke veštine (slušanje, govor, razumevanje i pisanje), ipak se primećuje veći broj dijaloga (u pisanoj ili audio-formi) i zadataka koji stimulišu rad u paru ili u grupi, u odnosu na vežbe koje imaju za cilj samostalno pismeno izražavanje na italijanskom jeziku.

\section{ANALIZA ELEMENATA KULTURE I CIVILIZACIJE}

Kako bismo utvrdili u kojoj meri su zastupljeni kulturološki i civilizacijski elementi u Video-kursu i kratkim tekstualnim celinama pod nazivom Kulturološki kafe u udžbeniku Nuovo Espresso 1, podelili smo naš korpus na pet celina: kulturno-istorijske znamenitosti i geografski pojmovi; gastronomija; običaji, navike i verovanja; tipični verbalni izrazi; te tipični neverbalni izrazi. Kroz detaljnu analizu izdvojenih celina, pokazaće se da su autori, osim razvijanja komunikativne kompetencije, imali na umu i relevantnost razumevanja italijanskih kulturoloških obeležja, te sticanje interkulturalne kompetencije kod učenika italijanskog jezika kao stranog.

\footnotetext{
${ }^{8}$ U okviru udžbenika Espresso 1 samo nakon nekih lekcija (konkretno 2, 5, 7. i 10. lekcije), predstavljeni su određeni elementi italijanske kulture i civilizacije. Primećuje se da su ovde teme i tekstovi u okviru Kulturološkog kafea leksički i sadržajno zahtevniji u odnosu na prerađeno izdanje.
} 


\begin{tabular}{|c|c|c|}
\hline $\begin{array}{c}\text { ELEMENTI KULTURE I } \\
\text { CIVILIZACIJE U } \\
\text { UDŽBENIKU NUOVO } \\
\text { ESPRESSO } 1\end{array}$ & VIDEO CORSO & CAFFÈ CULTURALE \\
\hline $\begin{array}{l}\text { KULTURNO-ISTORIJSKE } \\
\text { ZNAMENITOSTI I } \\
\text { GEOGRAFSKI POJMOVI }\end{array}$ & $\begin{array}{l}\text { VC1: 14-15; VC2: 28-29; } \\
\text { VC3: 44-45; VC4: 56-57; } \\
\text { VC5: 70-71; VC6: 86-87; } \\
\text { VC8: 114-115; VC9: 126- } \\
\text { 127; VC10: 140-141 }\end{array}$ & $\begin{array}{l}\text { CC2: 29; CC4: 58; CC7: } \\
101\end{array}$ \\
\hline GASTRONOMIJA & $\begin{array}{l}\text { VC4: 56-57; VC5: 70-71; } \\
\text { VC8: 114-115 }\end{array}$ & CC3: 46; CC8: 116 \\
\hline $\begin{array}{l}\text { OBIČAJI, NAVIKE I } \\
\text { VEROVANJA }\end{array}$ & $\begin{array}{l}\text { VC6: 86-87; VC7: 100- } \\
\text { 101; VC8: 114-115; VC10: } \\
\text { 140-141 }\end{array}$ & $\begin{array}{l}\text { CC1: 16; CC3: 46; CC5: } \\
\text { 71; CC6: 88; CC8: 116; } \\
\text { CC9: } 128\end{array}$ \\
\hline TIPIČNI VERBALNI IZRAZI & $\begin{array}{l}\text { VC1: 14-15; VC2: 28-29; } \\
\text { VC3: 44-45; VC4: 56-57; } \\
\text { VC5: 70-71; VC6: 86-87; } \\
\text { VC8: 114-115; VC9: 126- } \\
\text { 127; VC10: 140-141 }\end{array}$ & CC1: 16 \\
\hline $\begin{array}{l}\text { TIPIČNI NEVERBALNI } \\
\text { IZRAZI }\end{array}$ & $\begin{array}{l}\text { VC4: 56-57; VC5: 70-71; } \\
\text { VC7: 100-101; VC8: 114- } \\
\text { 115; VC9: 126-127 }\end{array}$ & CC10: 141 \\
\hline
\end{tabular}

Tabela 1. Elementi kulture i civilizacije u udžbeniku Nuovo Espresso 1

Najznačajniji geografski podaci o Italiji predstavljeni u Kulturološkom kafeu vezani su za aktivnosti kroz koje učenici treba da se upoznaju s brojem stanovnika, brojem regija, te najvećim italijanskim gradovima prikazanim na mapi Italije (CC2: 29), kao i turističkim atrakcijama (CC4: 58 i CC7: 101). U Kulturološkom kafeu koji prati četvrtu nastavnu celinu (CC4: 58), učenicima su predstavljene kulturno-istorijske znamenitosti nekoliko čuvenih italijanskih gradova (Sikstinska kapela u Rimu, Galerija Ufici u Firenci, katedrala Duomo u Milanu, Trg Svetog Marka u Veneciji, te arheološko nalazište Pompeja). Uporedo sa usvajanjem nove leksike iz oblasti geografije i putovanja (CC7: 101), učenici dobijaju priliku da nauče nešto više o lokalitetima kao što su Činkve Tere, jezero Garda, ostrva Iskija, Kapri i Pročida, srednjovekovni gradići San Điminjano i Areco, te brdoviti predeli regija Kjanti i Frančakorta, čuveni po istoimenim vinima. Kada je reč o Video-kursu, u čak osam epizoda prikazana je Firenca sa nekim od

\footnotetext{
${ }^{9} \mathrm{U}$ daljem tekstu ćemo koristiti navedene skraćenice.
} 
svojih najznačajnijih znamenitosti. Preostale dve epizode smeštene su u drugačiji kontekst - predstavljeni su Pistoja (VC6: 86-87) i tipični krajolik u unutrašnjosti Toskane (VC5).

Polazeći od pretpostavke da je učenicima na početnom nivou učenja italijanskog jezika poznato da je hrana važan element italijanskog kulturnog identiteta, autori udžbenika posvetili su značajnu pažnju gastronomiji. Osim toga što je čitava jedna nastavna jedinica u knjizi posvećena isključivo hrani, analizirani korpus obiluje kulturološkim i civilizacijskim elementima iz oblasti gastronomije. Kako bi proces usvajanja italijanske kulture bio olakšan, učenici imaju priliku da se i kroz video-epizode (VC4: 56-57; VC8: 114-115) upoznaju s prehrambenim navikama Italijana. Kulturološki kafe (CC3: 46) nudi pregled ugostiteljskih objekata u Italiji (bar, restoran, tratorija, picerija, itd.), s posebnim osvrtom na razlike među njima. Pored toga što ima za cilj obnavljanje morfosintaksičkih struktura obrađenih u prethodnoj nastavnoj jedinici, te usvajanje novog vokabulara, Kulturološki kafe (CC8: 116), kroz prikaz tipičnih italijanskih prehrambenih proizvoda, podstiče kod učenika razvoj interkulturalne kompetencije, kao i usvajanje novih elemenata italijanske kulture ${ }^{10}$.

Kulturni modeli vezani za običaje, navike i verovanja Italijana zastupljeni su u zadovoljavajućoj meri u Video-kursu i Kulturološkom kafeu. Kroz videoepizode, učenici stiču različita saznanja - od toga da Italijani imaju dvokratno radno vreme s pauzom za ručak (VC6: 86-87) i da se, kao prijatelji, srdačno pozdravljaju (VC10: 140-141), preko uvida u ono što kupuju u delikatesnoj radnji, do toga kako plaćaju na kasi (VC8: 114-115). Kultura pozdravljanja kod Italijana (uz poljupce i zagrljaje, naročito između rodbine i prijatelja), načini plaćanja (napojnica i plaćanje računa u baru), važnost koju trg ima u društvenom, političkom i kulturnom životu Italijana, te tradicija prazničnih darovanja, takođe su predstavljeni u okviru Kulturološkog kafea (CC1: 16; CC5: 7; CC6: 88; CC9: 128).

Premda se u Kulturološkom kafeu može uočiti tek nekoliko tipičnih verbalnih izraza (CC1: 16), Video-kurs nudi nekoliko ovakvih (za Italijane veoma karakterističnih) izraza, što ukazuje na nameru autora da se učenicima, kroz multimedijalni format, što bolje približi (nova) leksika iz datih nastavnih jedinica. Predstavljanjem realnih životnih situacija kroz audio-vizuelni materijal, učenicima

10 Studenti imaju zadatak da fotografije na kojima su prikazani tipični prehrambeni proizvodi (gianduiotto, parmigiano reggiano, mozzarella, prosciutto di Parma, olio d'oliva, tortellini, chianti) povežu s odgovarajućim detaljnim opisom. 
se olakšava usvajanje elemenata strane kulture. Akteri kratkih epizoda u okviru Video-kursa učestalom upotrebom karakterističnih verbalnih izraza svaki put iznova podsećaju učenike kako da obogate svoju komunikaciju na italijanskom jeziku. Među najčešćim tipičnim verbalnim izrazima izdvojili bismo: Oh, mamma! - Majko mila! (VC1); va be' - važi, dobro; Che piacere! - Kakvo zadovoljstvo!; Ma dai! - Ma daj! (VC2); allora - dakle (VC3); boh - hm! tja! ama... (izražava nedoumicu); anzi - čak / naprotiv; Che ore sono? - Koliko je sati? (VC4); senti / senta - čuj / čujte (VC5); a sinistra / a destra - levo / desno (VC6); In bocca al lupo! - Nek je sa srećom! (VC9); Ma va'! - Hajde molim te! / Svašta! (VC10).

Budući da su neodvojivi deo komunikacije kod Italijana, tipični neverbalni izrazi zastupljeni su u zadovoljavajućoj meri za početni nivo učenja italijanskog jezika. Učenici imaju prilike da vide mnogobrojne italijanske gestove, propraćene facijalnim ekspresijama, u pet video-epizoda (VC4, VC5, VC7, VC8, VC9). Zbog neospornog značaja gestova u italijanskoj komunikaciji, opredelili smo se da na kraju našeg rada predstavimo Kulturološki kafe pod nazivom Conosci i gesti italiani? - Poznaješ li italijanske gestove? (CC10: 141), koji je u celosti posvećen gestovima.

Kroz nastavnu aktivnost u kojoj treba da povežu značenja šest gestova $\mathrm{s}$ odgovarajućim fotografijama, učenici dobijaju priliku da savladaju osnovne gestove koje Italijani koriste u svakodnevnoj komunikaciji. Autori su se opredelili za sledeće gestove: 1. Quello è matto! - Ma, ovaj je lud!; 2. Non mi interessa per niente! - Uopšte me ne zanima!; 3. Ma cosa vuoi? - Ma, šta ti hoćeš?; 4. È ora di andare. - Vreme je da idem / da se ide.; 5. Buona fortuna! - Srećno!; 6. Ci vediamo dopo! - Vidimo se kasnije! 


\section{caffè culturale}

Conosci i gesti italiani?

a. Inserisci nel balloon la frase che il gesto esprime.
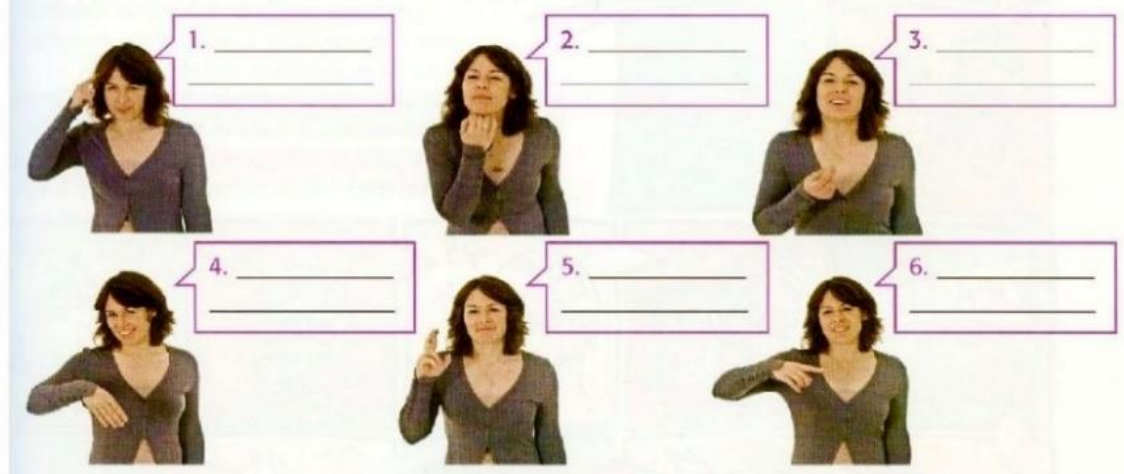

a Non mi intercssa per niente!

buello è matto!

C Buona fortuna!

d Ci vediamo dopo!

Ea cosa vuoi?

I E ora di andare.

b. E nel tuo Paese? Quali sono i gesti per le espressioni del punto a.? Ci sono gesti simili che hanno però un significato diverso?

Fotografija 1. Kulturološki kafe 10 - Poznaješ li italijanske gestove?

(Ziglio \& Rizzo 2015: 141)

Premda ograničen, izbor italijanskih gestova u udžbeniku izuzetno je zanimljiv, a u praksi se pokazao veoma efikasnim za uporedno učenje jezika i kulture. Imajući u vidu da se kroz učenje gestova, brže i lakše usvajaju ne samo modeli neverbalne komunikacije, već i elementi verbalne komunikacije (gramatika i leksika), predlažemo da se sadržaj udžbenika Nuovo Espresso 1 dopuni dodatnim materijalom koji bi obuhvatio još neke italijanske tipične neverbalne izraze.

\section{ZAKLJUČAK}

Predmet rada bila je analiza zastupljenosti kulturoloških i civilizacijskih elemenata u namenski osmišljenom video i tekstualnom sadržaju u okviru udžbenika Nuovo Espresso 1. Kao što je već navedeno, ove elemente grupisali smo u pet celina: kulturno-istorijske znamenitosti i geografski pojmovi; gastronomija; običaji, navike i verovanja; tipični verbalni izrazi; te tipični neverbalni izrazi. Imajući u vidu njihov značaj za razvoj interkulturalne kompetencije, pokušali smo da utvrdimo kako i koliko ovi elementi doprinose kvalitetu nastavnog procesa, te usvajanju strane kulture. Dok tekstualni sadržaj Kulturološkog kafea podstiče razvoj interkulturalne kompetencije kroz aktivnosti u kojima učenik treba da uoči sličnosti i razlike između svoje i ciljne 
kulture, Video-kurs je osmišljen kao multimedijalni prikaz strane kulture s kojom se učenik susreće na početnom nivou učenja italijanskog jezika kao stranog. Najzastupljeniji elementi italijanske kulture i civilizacije u video i tekstualnim sadržajima jesu gastronomija i geografija, dok su običaji, navike i verovanja Italijana prikazani u zadovoljavajućoj meri. Uočili smo da su tipični verbalni i neverbalni izrazi prikazani prvenstveno u Video-kursu, što nas navodi na zaključak da su autori imali nameru da ove elemente predstave u multimedijalnom obliku, kako bi učenicima olakšali njihovo razumevanje i usvajanje. U udžbeniku Nuovo Espresso 1 uopšte nisu zastupljeni kulturološki i civilizacijski elementi iz oblasti umetnosti (muzički, likovni i filmski sadržaji), kao ni znamenite ličnosti Italije.

Nakon sprovedene analize, zaključujemo da su sadržaji u prikazanim video- i tekstualnim celinama adekvatno odabrani za početni nivo učenja italijanskog jezika kao stranog. Međutim, ukoliko se u procesu učenja/nastavi italijanskog jezika na ovom nivou koristi udžbenik Nuovo Espresso 1, valjalo bi upotpuniti namenski osmišljene video i tekstualne celine, koje su bile predmet analize našeg rada, nedostajućim elementima kulture i civilizacije. Pored uvođenja dodatne literature prilagođene nivou znanja učenika (Vučo 2003: 161), predlažemo da se, u skladu sa interesovanjem učenika, nastava obogati multimedijalnim sadržajima iz oblasti italijanske muzike (YouTube linkovi sa pesmama), filma (inserti iz čuvenih filmova italijanske kinematografije), reprodukcijama poznatih umetničkih dela, te kratkim video i ppt prezentacijama o znamenitim ličnostima Italije. Pored vešto odabranog dopunskog didaktičkog materijala, za proces interkulturalne kompetencije ključna je figura nastavnika, čija uloga podrazumeva $i$ isticanje sličnosti između sopstvene i strane kulture, kao i isticanje lepote različitosti, što bi trebalo da doprinese prevazilaženju eventualnih pogrešnih predstava o drugoj kulturi.

\section{IZVORI}

Ziglio, L., Rizzo, G. (2015). Nuovo Espresso 1. Firenze: Alma Edizioni.

Ziglio, L., Rizzo, G. (2008). Espresso 1. Firenze: Alma Edizioni.

\section{LITERATURA}

Balboni, P. (2008). Cultura, civiltà e interculturalità. Pristupljeno 28. 8.2020. URL: <http://www.chersi.it/listing/neoassunti2008/6lingua_straniera/ 1361.pdf >.

Bugarski, R. (2005). Jezik i kultura. Beograd: Biblioteka XX vek. 
Bugarski, R. (2006). Kultura i Jezik, u Susret kultura, ur. Lj. Subotić, M. Kleut, N. Bugarski (Novi Sad: Filozofski fakultet): 31-37.

Dudaš, B. (2006). Kulture i identitet. O njihovom problematičnom odnosu, u Susret kultura, ur. Lj. Subotić, M. Kleut, N. Bugarski (Novi Sad: Filozofski fakultet): $159-170$.

Durbaba, O. (2016). Kultura i nastava stranih jezika: uvod u interkulturnu primenjenu lingvistiku. Beograd: Filološki fakultet.

Đorović, D. (2014). Specifičnosti nastave italijanskog jezika za studente društvenih i humanističkih nauka na Filozofskom fakultetu $\mathrm{u}$ Beogradu, $\mathrm{u}$ Jezici $u$ obrazovanju i jezičke obrazovne politike, ur. J. Filipović, O. Durbaba (Beograd: Filološki fakultet) 249-267.

Đurić Bosnić, A., Đurić, M. \& Tomašević T. (2021). Isto i različito: kratki vodič kroz interkulturalno obrazovanje. Beograd: Impresum.

Jovičić, S., Kašić, Z., Đorđević, M. (2006). Paralingvističke i ekstralingvističke informacije u govornim tehnologijama, u Zbornik radova 50. Konferencije za ETRAN, tom II (Beograd): 443-449. Pristupljeno 12.3.2021. URL: <https://www.etran.rs/common/archive/ETRAN_1955-2006/ET(R)AN_19552006/eTRAN/50.ETRAN.2006.2/AK/Jovicic\%20Kasic\%20Djordjevic. ETRAN2006.pdf>.

Livolsi, M. (2011). Chi siamo, La difficile identità nazionale degli italiani, Milano: Franco Angeli.

Marić, A. (2006). Uticaj međujezičkih razlika na učenje bliskih jezika, u Susret kultura, ur. Lj. Subotić, M. Kleut, N. Bugarski (Novi Sad: Filozofski fakultet): 909-917.

Momčilović, N. (2013). Interkulturalnost i nastava stranih jezika, u Od nauke do nastave, ur. B. Dimitrijević (Niš: Filozofski fakultet): 523-535.

Stanić, T., Blatešić, A. (2019). Književni i civilizacijski elementi u udžbenicima italijanskog jezika Nuovo Espresso, u Susret kultura, ur. Ž. Milanović (Novi Sad: Filozofski fakultet): 325-338.

Trebješanin, Ž., Žikić, B. (2015). Neverbalna komunikacija: antropološko-psihološki pristup. Beograd: Zavod za udžbenike.

Tylor, B. E. (1920). Primitive culture. London: John Murray, Albemarle Street.

Vilić, I. (2006). Kontakt sa kulturom i civilizacijom u procesu učenja stranog jezika, u Susret kultura, ur. Lj. Subotić, M. Kleut, N. Bugarski (Novi Sad: Filozofski fakultet): 905-908. 
Vučo, J. (2013). Udžbenici italijanskog jezika za univerzitetsku nastavu, u Udžbenik u nastavi stranih jezika, ur. M. Vuković, V. Kilibarda, B. Šekularac, J. Vučo (Nikšić: Univerzitet Crne Gore): 149-161.

Ziglio, L., Rizzo, G. (2001). Nuovo Espresso 1: guida per l'insegnante. Firenze: Alma Edizioni.

Jelena Badovinac

University of Novi Sad

Faculty of Philosophy

$\mathrm{PhD}$ program in Language and Literature

Nebojša Vlaškalić

University of Novi Sad

Faculty of Philosophy

\section{ELEMENTS OF CULTURE AND CIVILIZATION IN THE ITALIAN LANGUAGE TEXTBOOK NUOVO ESPRESSO 1 - VIDEO CORSO AND CAFFÈ CULTURALE}

\section{Summary}

In this research, we singled out the elements of Italian culture and civilization presented in short videos (Video corso) and separate, intentionally designed, textual units (Caffe culturale) that accompany all teaching units in the Italian language textbook Nuovo Espresso 1. The aim of this research was to analyze this corpus and emphasize its didactic usefulness in the process of learning and acquisition of Italian culture. Keeping in mind the variety of material that we analyzed, we divided our corpus into five thematic units (landmarks and geographical terms; gastronomy; custom, habits and beliefs; typical verbal expressions; and typical non-verbal expressions) in order to present more clearly how learning a foreign language is inseparable from learning about its culture. After exploring the correlations between language, culture and civilization in the first section of this paper, we dedicated the second part of our research to foreign language learning and intercultural competence. The third section was dedicated to verbal and non-verbal communication as part of Italian culture. We described and analyzed the corpus in the final section. Through textual and video presentations we emphasized how the cultural aspects of language complement each other and facilitate the process of learning Italian language and culture at the elementary level. This approach contributed to better intercultural competence when communicating with native speakers.

Key words: Italian language and culture, foreign language acquisition, intercultural competence, communication, video and text.

Primljeno: 30. 4. 2021.

Prihvaćeno: 13. 7. 2021. 